\title{
The linear quadratic regular algorithm-based control system of the direct current motor
}

\author{
Trong-Thang Nguyen \\ Faculty of Energy Engineering, Thuyloi University, Vietnam
}

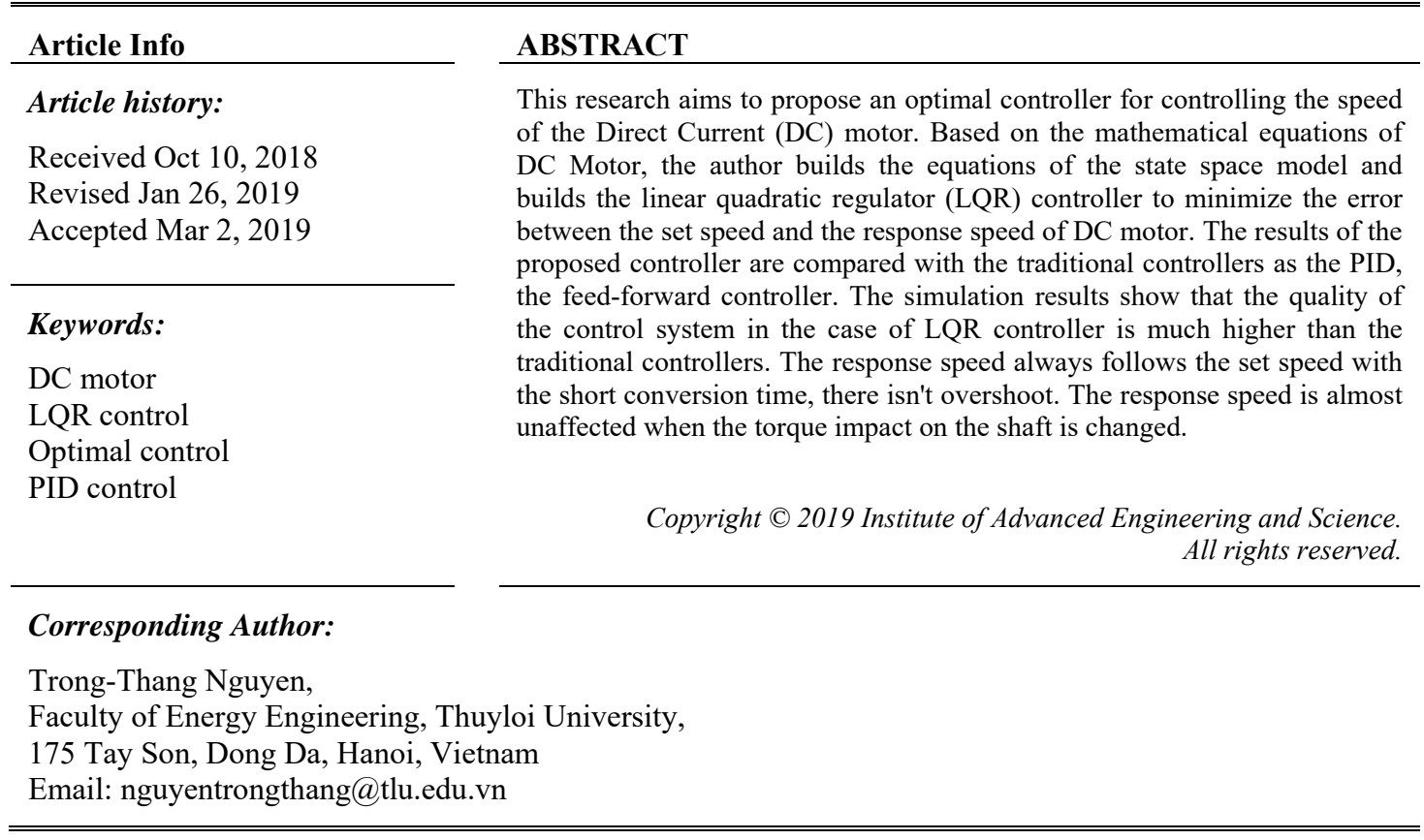

\section{INTRODUCTION}

The DC motor is a traditional electric motor. In comparison to the other electric motor such as brushless DC motors [1-3], induction machine [4-6], the DC motor has the intrinsic advantages such as the ease of maintenance, the large electromagnetic torque, the simple control structure and the adjust ability of the speed in a wide range. Thus, the DC motor is still very popular in the application of industrial areas required the high-quality motion, such as mining, transportation, steel rolling, etc. So, it is very important to enhance the performance of the DC motor control system. There are many studies on the DC motor control such as [7-10]. Most of these studies use a simple controller such as Proportional-Integral-Derivative (PID) controllers. The advantage of the PID control is a simple structure, but the drawback is that the quality of the control system is not high. The research [11] have proposed a solution to control the DC motor that has achieved high-quality, it is the control method based on the flatness principle, but the limitation of this method is that the control algorithm is complex.

To overcome all the limitations of the previous method, in this study, the author proposes a solution to build a control system based on the linear quadratic regulator controller. The control algorithm is simple and the quality is optimized. By using LQR controller, the deviation of the DC Motor speed can be minimized, and the response speed is not changed when the disturbance such as shaft torque is changed.

The LQR control method is used to control a lot of objects in practice as two-wheels self-balancing mobile robot [12-14], converter [15-17], quad-rotor [18-20], wind power generator [21, 22]. The Linear Quadratic Regulator method is setting the controller by using a mathematical algorithm to minimize the cost function with weighting factors defined by the designer. The cost-function is often defined as a sum of the deviations of response output and their desired values [23, 24]. 


\section{THE LQR CONTROL SYSTEM}

Considering the object with state equation:

$$
\dot{x}(t)=A \cdot x(t)+B \cdot u(t)
$$

where: $x(t)=\left[x_{1}(t), x_{2}(t), \ldots, x_{n}(t)\right]$ is the vector of state signal,

$u(t)=\left[u_{1}(t), u_{2}(t), \ldots, u_{m}(t)\right]$ is the vector of control signal.

The requirement of the control system is to find the control signal $u(t)$ in order for the control object from the initial state $x\left(t_{0}\right)=x(0)$ go to the end state $x\left(t_{f}\right)=0$ and satisfy the following condition (cost functional):

$$
J=\frac{1}{2} x^{T}\left(t_{f}\right) \cdot M \cdot x\left(t_{f}\right)+\frac{1}{2} \int_{t_{0}}^{t_{f}}\left[x^{T}(t) \cdot Q \cdot x(t)+u^{T}(t) \cdot R \cdot u(t)\right] d t \rightarrow \min
$$

Where $Q$ and $\mathrm{M}$ are the symmetric, positive semi-definite weight matrix. $R$ is the symmetric, positive definite weight matrix.

To solve the problem, we establish the Hamilton function:

$$
H=\frac{1}{2}\left[x^{T}(t) \cdot Q \cdot x(t)+u^{T}(t) \cdot R \cdot u(t)\right]+\lambda^{T}[A \cdot x(t)+B \cdot u(t)]
$$

The optimal experiment is the solution of the following equations:

- The state equation:

$$
\dot{x}(t)=A \cdot x(t)+B \cdot u(t)
$$

- The equilibrium equation:

$$
\dot{\lambda}(t)=-\frac{\partial H}{\partial x}=-Q \cdot x(t)-A \cdot \lambda^{T}(t)
$$

- The optimal condition:

$$
\frac{\partial H}{\partial u}=R \cdot u(t)+B^{T} \cdot \lambda^{T}(t)=0
$$

From equation (6), we have:

$$
u(t)=-R^{-1} \cdot B^{T} \cdot \lambda^{T}(t)
$$

Replace $u(t)$ into (4), we have:

$$
\dot{x}(t)=A \cdot x(t)-B \cdot R^{-1} \cdot B^{T} \cdot \lambda^{T}(t)
$$

Combining (8) and (5) we have:

$$
\left[\begin{array}{c}
\dot{x}(t) \\
\dot{\lambda}(t)
\end{array}\right]=\left[\begin{array}{cc}
A & -B \cdot R^{-1} \cdot B^{T} \\
-Q & -A
\end{array}\right]\left[\begin{array}{l}
x(t) \\
\lambda^{T}(t)
\end{array}\right]
$$

Solving the above equations, we have the optimal control signal:

$$
u^{*}(t)=-K(t) \cdot x(t)
$$


Where $K(t)=R^{-1} \cdot B^{T} \cdot P(t)$

$P(t)$ is the positive semi-definite solution of the Riccati equation:

$-\dot{P}=P \cdot A+A^{T} \cdot P+Q-P \cdot B \cdot R^{-1} \cdot B^{T} \cdot P$

In the case of the infinite time $t_{f}=\infty$, the cost function is as follows:

$J=\frac{1}{2} \int_{0}^{t_{f}}\left[x^{T}(t) \cdot Q \cdot x(t)+u^{T}(t) \cdot R \cdot u(t)\right] d t \rightarrow \min$

The optimal control signal:

$u^{*}(t)=-K \cdot x(t)$

Where $K=R^{-1} \cdot B^{T} \cdot P$

$P$ is the positive semi-definite solution of the Riccati equation:

$P . A+A^{T} . P+Q-P \cdot B \cdot R^{-1} \cdot B^{T} \cdot P=0$

( $K$ and $P$ do not depend on the time)

\section{THE DIAGRAM AND THE EQUTIONS OF THE DC MOTOR}

The diagram of a separately excited DC Motor is presented as Figure 1 [25] it includes:

- $\quad$ The field windings are in the stator, they are used to excite the field flux.

- The armature coils are on the rotor, they are supplied current via brush and the commutator.

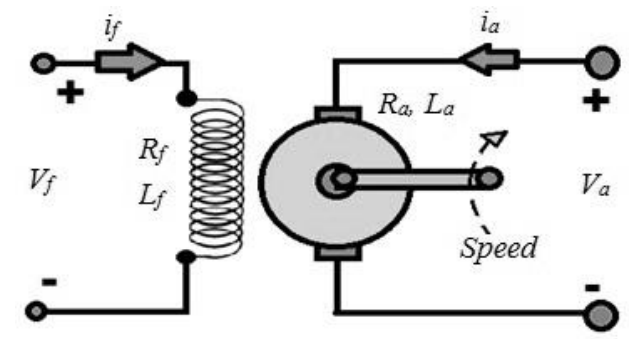

Figure 1. The diagram of a separately excited DC Motor

The mathematical equations of the DC Motor include:

- The voltage equation:

$$
V_{a}=R_{a} i_{a}+L_{a} \frac{d i_{a}}{d t}+E(\mathrm{~V})
$$

Where $V_{a}$ is the armature voltage, which is fed into the armature coil; $R_{a}, L_{a}$ is the armature resistance and inductance, $E$ is the electromotive.

- The electromotive equation:

$$
E=K_{E} \omega=\left(L_{a f} . i_{f}\right) \cdot \omega(\mathrm{V})
$$


Where $\omega$ is the speed of the rotor, $K_{E}$ is the coefficient of voltage, $i_{f}$ is the winding field current, $L_{a f}$ is the field armature mutual inductance.

- The motion equation:

$$
J \frac{d \omega}{d t}=T_{e}-T_{L}-B_{m} \omega-T_{f}(\mathrm{~N} . \mathrm{m})
$$

Where $J$ is the inertia, $T_{e}$ is the electromechanical torque, $T_{L}$ is the torque which impact to the shaft, $B_{m}$ is the coefficient of the viscous friction, $T_{f}$ is the coulomb friction torque.

- The electromechanical torque equation:

$$
T_{e}=K_{T} i_{a}=\left(L_{a f} \cdot i_{f}\right) \cdot i_{a}(\mathrm{~N} . \mathrm{m})
$$

Where $K_{T}$ is the coefficient of the torque.

Based on the equations of the DC Motor, we build the model diagram of DC Motor as shown in Figure 2.

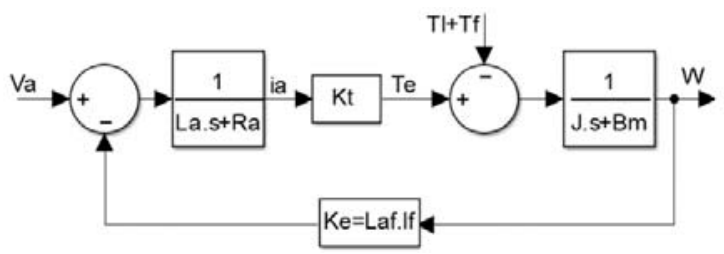

Figure 2. The model diagram of DC Motor

The parameters of the DC Motor in this study are shown in Table 1.

Table 1. The DC Motor parameters

\begin{tabular}{lllllll}
\hline $\mathrm{Ra}(\Omega)$ & $\mathrm{La}(\mathrm{H})$ & $\mathrm{Kt}$ & $\mathrm{Ke}$ & $\mathrm{J}\left(\mathrm{kg} . \mathrm{m}^{\wedge} 2\right)$ & $\mathrm{Bm}(\mathrm{N} . \mathrm{m} . \mathrm{s})$ & $\mathrm{Tf}(\mathrm{N} . \mathrm{m})$ \\
\hline 0.5 & 0.011 & 0.2 & 0.1 & 0.2 & 0.1 & $\mathrm{Var}$ \\
\hline
\end{tabular}

To investigate the dependence of the Motor speed on the armature voltage, we set the armature voltage change from $\mathrm{Va}=75 \mathrm{~V}$ to $\mathrm{Va}=100 \mathrm{~V}$. To investigate the dependence of the Motor speed on the shaft torque, we set the shaft torque change from $T_{L}=10(\mathrm{~N} . \mathrm{M})$ to $T_{L}=20(\mathrm{~N} . \mathrm{M})$. Running the simulation model, we obtain the time characteristic of the speed shown in Figure 3.

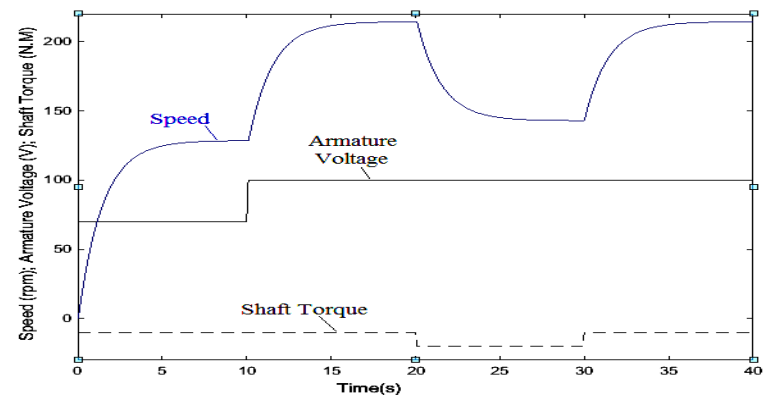

Figure 3. The time characteristic of the speed when changing the armature voltage and the shaft torque 
The mission of the system is to control the speed of the DC motor following the desired value. It also minimizes the change in speed when changing the torque impacted on the shaft of the DC Motor. In this study, the author proposes an optimal controller LQR to control the response speed following the set speed with the shortest conversion time.

\section{BUILDING THE CONTROL SYSTEM FOR THE DC MOTOR}

\subsection{The PI controller and feed-forward controller}

Based on the dependence of the Motor speed on the armature voltage and the shaft torque, the author built and tested the traditional controllers for DC motors as a basis for comparison with LQR controllers. The first controller is a Feed-forward controller with the gain coefficient $K=2.14$. The second controller is the PI controller, the control system model shown in Figure 4.

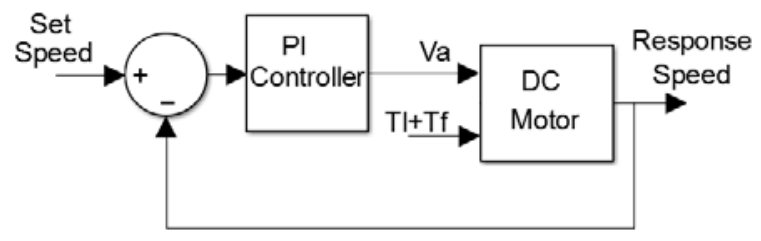

Figure 4. The control system model with the PI controller

The parameters of the PI controller are determined experimentally. We define the appropriate parameters in order that the quality of the control system is good. Finally, the PI controller parameters are defined as follows: $\mathrm{Kp}=1, \mathrm{Kp}=5$

Running the system in two cases of the controller (PI and Feed-forward), the simulation result is shown as Figure 5.

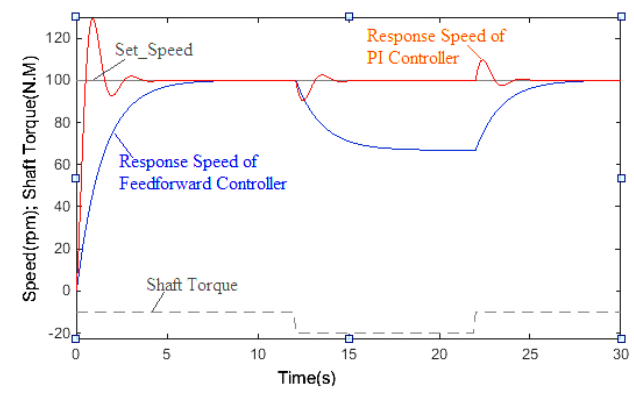

Figure 5. The simulation result in the cases of Feed-forward and PI controller

The simulation results show that the Feed-forward controller has met the control requirement. The response speed of the DC motor has been following the set speed. However, the quality of control system is low. In particular, the response speed of the DC Motor is not maintained when changing the torque impacted on the shaft. This will have a very negative effect when applying in the electric motion of the production process. In the case of the PI controller, the control quality has been improved a lot. The response speed has been followed the set speed with the short transition time, and it is maintained when changing the torque impacted on the shaft. However, the limitations are that there is the overshot, and there is oscillation before the response speed is stable.

Thus, the author proposes an optimal controller (LQR) to address these limitations and improve the quality of the control system.

Int J Pow Elec \& Dri Syst, Vol. 10, No. 2, June 2019: $768-776$ 


\subsection{The optimal LQR controller}

From the equations of DC Motors, changing into the state equations with the state variables that are the armature current and the rotor speed:

$$
\left\{\begin{array}{l}
\frac{d \omega}{d t}=-\frac{B_{m}}{J} \omega+\frac{K_{T}}{J} i_{a}-\frac{1}{J} T_{L}-\frac{1}{J} T_{f} \\
\frac{d i_{a}}{d t}=-\frac{K_{E}}{L_{a}} \omega-\frac{R_{a}}{L_{a}} i_{a}+\frac{1}{L_{a}} V_{a}
\end{array}\right.
$$

To increase the efficiency of the control process, we add the state variable $(\omega / s)$ to the state equations:

$$
\left\{\begin{array}{l}
\frac{d(\omega / s)}{d t}=\omega \\
\frac{d \omega}{d t}=-\frac{B_{m}}{J} \omega+\frac{K_{T}}{J} i_{a}-\frac{1}{J} T_{L}-\frac{1}{J} T_{f} \\
\frac{d i_{a}}{d t}=-\frac{K_{E}}{L_{a}} \omega-\frac{R_{a}}{L_{a}} i_{a}+\frac{1}{L_{a}} V_{a}
\end{array}\right.
$$

In the above state equations, the state variables are $x=\left(x_{1}, x_{2}, x_{3}\right)=\left(\omega / s, \omega, i_{a}\right)$, the control signal is $V_{a}$. The torque $T=-\frac{1}{J} T_{L}-\frac{1}{J} T_{f}$ is the noise.

We design the control signal $u(t)=-K_{L Q R} \cdot x(t)$ in order for $\lim _{t \rightarrow \infty}\left(x_{\text {response }}-x_{\text {set }}\right) \rightarrow 0$.

Named $x_{e}$ is the error between $x_{\text {response }}$ and $x_{\text {set }}$.

$x_{e}=\left(\Delta x_{1}=x_{1 \_ \text {response }}-x_{1 \_s e t}, \Delta x_{2}=x_{2 \text { response }}-x_{2_{-} \text {set }}, \Delta x_{3}=x_{3_{-} \text {response }} x-x_{3_{-} \text {set }}\right)$.

The state equation (20) is rewritten as follows:

$$
\dot{x}_{e}=A \cdot x_{e}+B . u
$$

Where $A=\left[\begin{array}{ccc}0 & 1 & 0 \\ 0 & -\frac{B_{m}}{J} & \frac{K_{T}}{J} \\ 0 & -\frac{K_{E}}{L_{a}} & -\frac{R_{a}}{L_{a}}\end{array}\right]=\left[\begin{array}{ccc}0 & 1 & 0 \\ 0 & -0.5 & 2 \\ 0 & -9.1 & -45.45\end{array}\right] ; B=\left[\begin{array}{c}0 \\ 0 \\ 1 \\ L_{a}\end{array}\right]=\left[\begin{array}{c}0 \\ 0 \\ 90.9\end{array}\right]$

In order for the response speed following the set speed with the short transition time, we define the optimal control signal LQR to minimize the goal function:

$J=\frac{1}{2} \int\left[x^{T}(t) \cdot Q \cdot . x(t)+u^{T}(t) \cdot R \cdot u(t)\right] d t \rightarrow \min$

With $Q=\left[\begin{array}{ccc}2 & 0 & 0 \\ 0 & 30 & 0 \\ 0 & 0 & 0\end{array}\right], R=0.02$.

The optimal control signal:

$u^{*}(t)=-K_{L Q R} \cdot x(t)$

Where:

$$
K_{L Q R}=R^{-1} \cdot B^{T} \cdot P
$$


$P$ is the positive semi-definite solution of the Riccati equation:

P.A $+\mathrm{A}^{\mathrm{T}} \cdot P+Q-P B R^{-1} \cdot B^{T} \cdot P=0$

Solving the equation (25) we have:

$P=\left[\begin{array}{lll}7.7821 & 0.1394 & 0.0022 \\ 0.1394 & 0.5380 & 0.0085 \\ 0.0022 & 0.0085 & 0.0002\end{array}\right]$

Replace P into (24), we have:

$K_{L Q R}=\left[\begin{array}{lll}10.0000 & 38.4622 & 0.8937\end{array}\right]$

The control system diagram is shown in Figure 6.

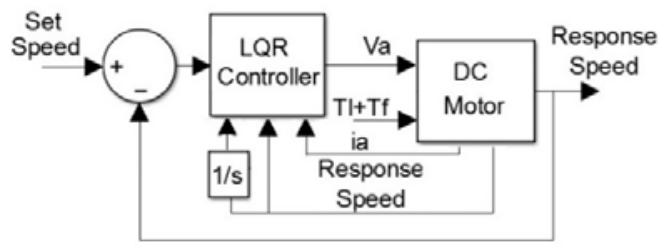

Figure 6. The control system diagram in the case of LQR controller

\section{RESULTS AND ANALYSIS}

We run the simulation model in the following cases: the Feed-forward controller, PI Controller, optimal LQR controller. The simulation results are shown in Figure 7.

The simulation results show that the quality of the control system in the case of using the optimal controller LQR is extremely better than that of the Feed-forward controller and the PI controller. In the case of the system with LQR controller, the response speed always follows to the set speed with a very short transition time, there is not overshot.

When changing the disturbance (shaft torque), the speed in case the Feed-forward controller is changed and is unrecoverable, the speed in the case of PI controller is changed and oscillated, after a time of about $4 \mathrm{~s}$, the response speed is restored. Especially in the case of the LQR controller, the response speed is almost unaffected by the change of the shaft torque. To more clearly show the different qualities in the different cases, the simulation results are zoom and shown in Figure 8.

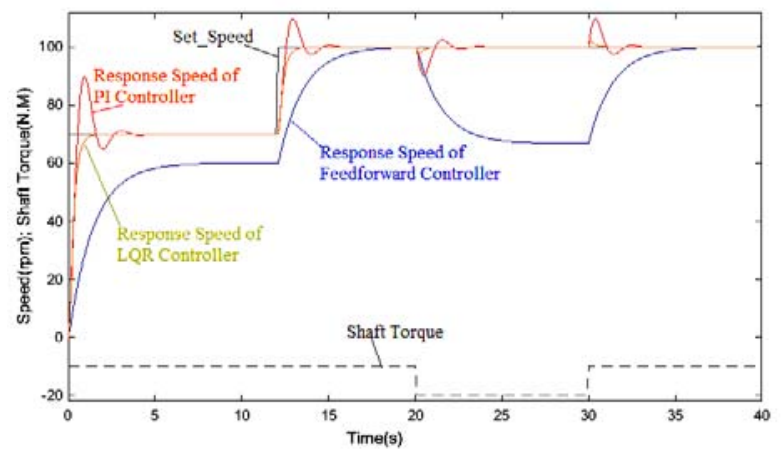

Figure 7. The simulation results in the different cases: Feed-forward, PI, LQR controller

Int J Pow Elec \& Dri Syst, Vol. 10, No. 2, June 2019: $768-776$ 


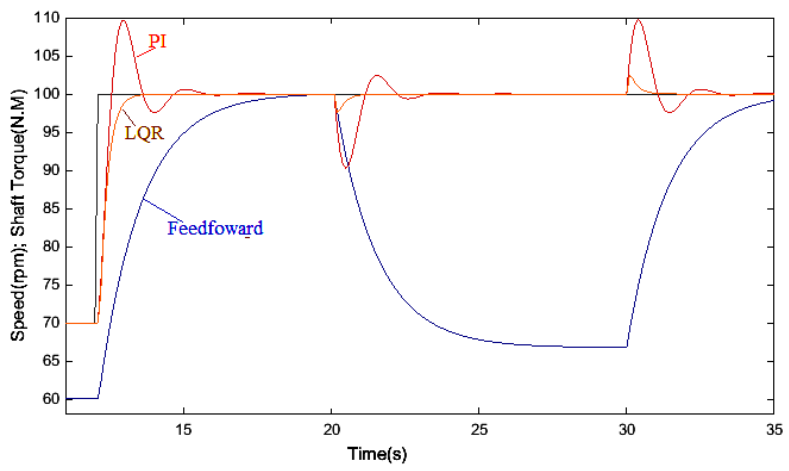

Figure 8 . The simulation results in the zoom view

\section{CONCLUSION}

In this study, the author has succeeded in building the optimal controller LQR for the DC Motor. The control quality of the proposed controller LQR is compared with the traditional controllers. The simulation results show that the system with LQR controller offers superior quality compared to traditional controllers. The response speed always follows to the set speed with a very short transition time. The response speed is almost unaffected when changing the shaft torque. Finally, the proposed controller has very simple control algorithms, but the quality is optimal. This is a good basis for applying control algorithm to electric motion using the DC Motor.

\section{REFERENCES}

[1] Park, J. S., \& Lee, K. D. "Design and Implementation of BLDC Motor with Integrated Drive Circuit". International Journal of Power Electronics and Drive Systems (IJPEDS), vol. 8(3), pp. 1109-1116; 2017.

[2] Trong, T. N., \& Duc, M. N. "The speed control system of BLDC using PID controller with PWM modulation technique". International Journal of Advanced and Appied Sciences, vol. 2(12), pp. 47-51; 2015.

[3] Sekhar, G. R., \& Banakara, B. "An Internal Current Controlled BLDC Motor Drive Supplied with PV Fed High", International Journal of Electrical and Computer Engineering (IJECE), vol 8(2), pp. 1262-1272; 2018

[4] Abdelhak, B., \& Bachir, B. "A High gain observer based sensorless nonlinear control of induction machine." International Journal of Power Electronics and Drive Systems (IJPEDS), 5(3), 305-314, 2015.

[5] Gunabalan, R., \& Subbiah, V. "Speed Sensorless Vector Control of Induction Motor Drive with PI and Fuzzy Controller." International Journal of Power Electronics and Drive Systems (IJPEDS), vol. 5(3), pp. 315-325, 2015.

[6] A. Ramesh, O. Chandra Sekhar, M. Siva Kumar, "A Novel Three Phase Multilevel Inverter with Single Dc Link For Induction Motor Drive Applications". International Journal of Electrical and Computer Engineering (IJECE), vol. 8(2), pp. 763-770. 2018

[7] Bosco, Maycon Chimini, et al,"Estimation of parameters and tuning of a speed PI of permanent magnet DC Motor using differential evolution", Electric Machines and Drives Conference (IEMDC), IEEE International, pp.1-6; 2017.

[8] Yao, Jianyong, Zongxia Jiao, and Dawei Ma,"Adaptive robust control of DC Motors with extended state observer", IEEE Transactions on Industrial Electronics Vol 61(7), pp. 3630-3637, 2014.

[9] Xue, Dingyu, Chunna Zhao, and YangQuan Chen, "Fractional order PID control of a DC-Motor with elastic shaft: a case study", American Control Conference, IEEE, pp.1-6, 2006.

[10] Thomas, Neenu, and Dr P. Poongodi, "Position control of DC Motor using genetic algorithm based PID controller", Proceedings of the World Congress on Engineering, vol. 2, pp. 1-3, 2009.

[11] Trong, T. N. "The Control Structure for DC Motor based on the Flatness Control". International Journal of Power Electronics and Drive Systems (IJPEDS), vol. 8(4), pp. 1814-1821, 2017.

[12] Xu, C., Li, M., \& Pan, F. The system design and LQR control of a two-wheels self-balancing mobile robot. In Electrical and Control Engineering (ICECE), 2011 International Conference on. IEEE. pp. 2786-2789, September, 2011.

[13] Zhao, J., \& Ruan, X. The LQR control and design of dual-wheel upright self-balance Robot. Intelligent Control and Automation, 4864-4869, 2008.

[14] Qiang, L., Ke-Ke, W., \& Guo-Sheng, W. "Research of LQR controller based on two-wheeled self-balancing robot. In Control and Decision Conference, 2009. CCDC'09. Chinese (pp. 2343-2348). IEEE.

[15] Zhang, M., Li, X., Liu, J., Su, H., \& Song, J. " Digital LQR steady-state optimal control with feedforward for nonminimum phase boost DC-DC converter". In Control and Decision Conference (CCDC), 2016 Chinese. IEEE. pp. 384-389, May 2016. 
[16] Rakhshani, E., Cantarellas, A. M., Remon, D., Luna, A., \& Rodriguez, P. "PSO-based LQR controller for multi modular converters." In ECCE Asia Downunder (ECCE Asia), 2013 IEEE, IEEE, pp. 1023-1027.June 2013.

[17] Olalla, C., Leyva, R., El Aroudi, A., \& Queinnec, I. "Robust LQR control for PWM converters: An LMI approach. IEEE Transactions on industrial electronics, Vol. 56(7), 2548-2558.

[18] Reyes-Valeria, E., Enriquez-Caldera, R., Camacho-Lara, S., \& Guichard, J. "LQR control for a quadrotor using unit quaternions: Modeling and simulation”. In Electronics, Communications and Computing (CONIELECOMP), 2013 International Conference on . IEEE. pp. 172-178, March 2013.

[19] Liu, C., Pan, J., \& Chang, Y. "PID and LQR trajectory tracking control for an unmanned quadrotor helicopter: Experimental studies". In Control Conference (CCC), 2016 35th Chinese. IEEE, pp. 10845-10850, July 2016.

[20] Khatoon, S., Gupta, D., \& Das, L. K. "PID \& LQR control for a quadrotor: Modeling and simulation". In 2014 International Conference on Advances in Computing, Communications and Informatics (ICACCI). IEEE, pp. 796802, September 2014.

[21] 16Slavov, T. P. T. "LQR power control of wind generator". In 2018 Cybernetics \& Informatics (K\&I). IEEE, pp. 16, January 2018.

[22] Li, J., Xu, H., Zhang, L., \& Hu, S. "Disturbance accommodating LQR method based pitch control strategy for wind turbines". In 2008 Second International Symposium on Intelligent Information Technology Application. IEEE, Vol. 1, pp. 766-770 December 2008.

[23] Friedland, B. "An introduction to state-space methods". Control System Design, pp. 3-16, 2005.

[24] Lewis, Frank L., Draguna Vrabie, and Vassilis L. Syrmos. Optimal control. John Wiley \& Sons, 2012.

[25] Trong-Thang Nguyen, "The neural network-based control system of direct current motor driver". International Journal of Electrical and Computer Engineering (IJECE), 9(2), pp. 1445-1452, 2019.

Int J Pow Elec \& Dri Syst, Vol. 10, No. 2, June 2019: $768-776$ 